\title{
Apontamentos sobre a inquietante estranheza de Inácio
}

\author{
Elizabeth da Penha Cardoso \\ Universidade de São Paulo
}

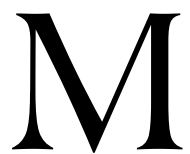

esmo desconhecendo ou discordando do conceito de unheimlich de Freud, é difícil discordar que a leitura de Inácio causa uma sensação de estranheza, contínua e aterradora. Vários elementos colaboram para essa impressão. A personagem que dá nome ao livro só é mencionada diretamente depois da página 70; Stela, mãe do narrador, e elemento mobilizador de toda a história, está morta desde o início, muitos a conheceram, mas as versões sobre ela são desconexas e incongruentes. Além disso, todos os atos torpes são plenamente justificáveis; os cenários, a maioria localizada na zona baixa carioca, são escuros, enfumaçados, sujos e habitados por figuras sinistras: prostitutas maternais com dente de ouro, atiradores profissionais, que nas horas vagas são palhaços e andam por aí com um esparadrapo em forma de cruz encima do nariz, donas de pensōes que lembram aves de rapina e gastam seu tempo assediando jovenzinhos órfãos e um homem misterioso, cruel, com poderes demoníacos de não envelhecer, de prever o futuro, de aparecer e desaparecer instantaneamente, de controlar a vida e a morte: Inácio. E, mais, todos eles, de uma forma ou de outra, acabam compondo uma família.

O narrador do livro é o febril Rogério, um rapaz de 19 anos, órfão, morador de pensões da Lapa, que não consegue livrar-se do passado, embora faça projeções para o futuro, apesar da saúde debilitada. Obcecado pelo retorno do pai e perseguido pelo amante da mãe, Rogério acaba remontando sua trajetória a partir de fragmentos da vida materna. Três personagens testemunham contraditoriamente sobre o destino dessa mulher: Violeta, freqüentadora de cabarés cariocas, considera Stela uma das "prostitutas mais cruéis do Rio de Janeiro"; já Lucas Trindade, seu ex-amante, a vê como esposa dedicada, e Inácio, ex-marido, julga-a infiel e a deixa na miséria. Morta, Stela não tem voz e cabe a Rogério concluir as motivações maternas para abandoná-lo. Entre bebedeiras e delírios, ele reencontra seus pais, de forma fugaz e dolorosa, 
e ao reatar os nós familiares perde-se de si mesmo, já que escreve seu relato durante a internação em um "sanatório", eufemismo para manicômio.

Com essa história a novela de Lúcio Cardoso, publicada em 1944, traz os ecos de uma época de horror e caos. Com as duas Guerras Mundiais e a proliferação de guerras civis, as quatro primeiras décadas do século XX formaram cenário para o mal tirar proveito dos benefícios da eficiência tecnológica e os seres humanos experimentarem a ausência do bem, banalizando a morte e as regras civilizatórias. Ao contar a trajetória de uma família que se desfaz nos becos da Lapa carioca, rompendo com vários preceitos morais do período, Lúcio Cardoso evoca a presença do mal, porém, de maneira sublinear, pois se trata do mal estabelecido, alastrado, daninho, que veio para ficar. Assim, no lugar de assustar, angustia; ao invés de amedrontar, enoja; ao contrário de afugentar, seduz e quando seduz intimida e o que era para esclarecer Rogério (o narrador) e o leitor confunde, criando suspense e uma inquietante sensação de estranheza.

O estranho, ao qual estamos nos referindo, é a tradução que unheimlich recebeu no Brasil; em espanhol optaram por lo ominoso, poderia ser também sospechoso, siniestro; em francês temos, l'inquiétante étrangeté, e em inglês optou-se por uncanny. Em artigo de 1919, o psicanalista empreende descrever o conceito de unheimlich por duas vias, uma lingüística, onde perfaz uma análise do uso dessa expressão em diversas línguas, e outra relacionando inúmeros casos e exemplos. Unheimlich é a palavra em alemão para o oposto de heimlich, doméstico, familiar, nativo. Portanto, unheimlich significa estrangeiro, não-familiar, estranho. A mais notável observação lingüística de Freud é sobre a ambivalência da palavra. Usada para descrever algo que causa estranheza, ela traz em sua grafia, e em seu sentido, o familiar, pois unheimlich não é apenas desconhecido e assustador, ele remete a algo doméstico, reconhecível, vivido, rememorável, porém estranho. O melhor exemplo freudiano é um pouco brusco, no entanto eficaz: os órgãos sexuais são tão heimlich (íntimos) que viram segredos, são ocultados com rigor e método até se tornarem unheimlich, estranhos, misteriosos, miraculosos. "heimlich é uma palavra cujo significado se desenvolve na direção da ambivalência, até que finalmente coincide com o seu oposto, unheimlich. Unheimlich é, de um modo ou de outro, uma subespécie de heimlich."

${ }^{1}$ FREUD, 1919/1996, p. 224. 
Psicanaliticamente o nó do texto freudiano está no recalque: “esse estranho não é nada novo ou alheio, porém algo que é familiar e há muito estabelecido na mente, e que somente se alienou desta através do processo da repressão". ${ }^{2}$ Entretanto não é a porção psicanalítica que nos interessa nesse trabalho de Freud, mas sim suas interações com a literatura para estabelecer o conceito. Leitor e escritor, o médico vienense lança mão da tradição literária em múltiplos momentos de seus escritos, nos quais encontramos Shakespeare, Dostoievski, Schelling, entre outros. Seu postulado mais famoso - complexo de Édipo - é devedor inafiançável de Sófocles. Para tratar do estranho apóiase em Hoffmann e em seu conto $O$ homem da areia. Aqui faremos o caminho inverso, pois não será a teoria apoiando-se no ficcional, mas sim a ficção solicitando os conceitos psicanalíticos. Veremos que os limites entre literatura e psicanálise proporcionam uma nova leitura de Inácio. Isto porque Freud não se contenta em conceituar unheimlich, mas quer também entender a maneira pela qual essa sensação se concretiza. "O estranho é aquela categoria do assustador que remete ao que é conhecido, de velho, e há muito familiar. Como isso é possível, em que circunstâncias o familiar pode tornar-se estranho e assustador, é o que mostrarei no que segue", promete Freud. ${ }^{3}$ Por nossa vez, nas confluências entre o literário e o psicanalítico, vamos aqui notar como Lúcio Cardoso constrói a inquietante estranheza de Inácio.

\section{A arquitetura do estranho}

Nos três últimos parágrafos do artigo de Freud chega-se ao ponto que mais nos interessa explorar. O psicanalista conclui que o sentimento de estranho na ficção está ligado, primeiro, ao posicionamento do narrador, pois o leitor precisa estar próximo do ponto de vista da personagem que sente a estranheza, e, segundo, aos recursos literários de que o escritor se vale para

\footnotetext{
${ }^{2}$ FREUD, 1919/1996, p. 258. Explicação que, como o próprio Freud alude, nos remete a noção de Schelling, que vê o "estranho como algo que deveria ter permanecido oculto mas veio à luz".

${ }^{3}$ FREUD, 1919/1996, p. 238.
} 
estabelecer o estranhamento; ele deve sustentar esse sentimento, sem alívio, sem remissão. ${ }^{4}$

Como já antecipamos algumas características da novela de Lúcio que favorecem a sensação de estranheza, vamos aprofundar um pouco nossa leitura e perceber o esmero do autor em criar um ambiente maléfico e estranho. O clima sinistro é, em parte, dado pelos cenários lúgubres e secretos (cassinos, prostíbulos, redutos de contraventores) e pela caracterização das personagens, mas alguns detalhes encontrados no trabalho com a linguagem reforçam, no leitor, a inquietante estranheza.

Comecemos pelo ponto de vista do narrador. Toda a novela representa uma espécie de diário de Rogério, que, internado num sanatório, parece entrar num processo psicanalítico e reconstrói sua história. É da perspectiva de Rogério que se acompanha todo o enredo, assim, por meio de seus delirantes sentidos, os acontecimentos mais cotidianos chegam até nós carregados de estranheza: uma mulher idosa, saindo do banho com uma toalha verde e felpuda sobre os ombros, torna-se um pássaro noturno; a simples menção de um nome pode desencadear sofrimento "às vezes mesmo de algo que não persistia mais no fundo da memória"; ${ }^{5}$ caminhar pelas ruas da Lapa faz surtir o efeito de "um sentimento de inquietação" e as roupas que as pessoas usam podem acarretar significados ocultos e monstruosos. A impressão de delírio ganha força do meio para o fim, pois, salvo uma alusão obscura de Violeta, ninguém além de Rogério e Lucas Trindade vê Inácio. ${ }^{6}$ Todas as vezes que eles se encontram ou se estabelece o caos, dificultando qualquer troca racional com outras testemunhas (como na cena da Feira de

4 “[...] por que é que a mão decepada na história do tesouro de Rhampsinitus não tem o estranho efeito que a mão cortada tem na história de Hauff. [...] A resposta é fácil. $\mathrm{Na}$ história de Heródoto, os nossos pensamentos estão muito mais concentrados na astúcia superior do chefe dos ladrōes, do que nos sentimentos da princesa. A princesa pode muito bem ter tido uma sensação estranha, na verdade provavelmente caiu desmaiada; mas nós não temos tal sensação, pois nos colocamos no lugar do ladrão, e não no lugar dela. [...]. FREUD, 1919/1996, p. 268.

${ }^{5}$ CARDOSO, 2002, p. 28.

${ }^{6}$ A partir dessa observação poderíamos até perguntar se Inácio seria um delírio de Rogério e Lucas, que leva o primeiro à loucura, matando o segundo. No entanto tal hipótese não será investigada no âmbito desse artigo. 
Amostras) ou estão misteriosa e providencialmente sozinhos. De toda forma, importa notar a sustentação do estranhamento pelo narrador em primeira pessoa localizado no limite entre a realidade e o delírio, susceptível até ao papel-de-parede de seu quarto. Mesmo quando outras personagens ganham voz é por meio da escrita de Rogério e seus sentidos agudos a qualquer sinal disparam a paranóia que sustenta nossa leitura até o final.

A organização das partes do enredo reforça o delírio do narrador e colabora com a percepção de estranheza. Nesse sentido, vale notar que no livro, o reencontro familiar dos Palmas está dividido em 21 capítulos e se dá nos múltiplos de sete - número cultuado por sua mística e envolto por milenares "coincidências", sete pecados capitais, sete livros do Velho Testamento, sete sacramentos, para ficarmos em poucas referências ao número na tradição católica, a qual Lúcio Cardoso conhecia bem. Então, temos na sétima parte da novela a cena na qual Rogério revê a mãe e, no capítulo 14, ele encontra o pai pela primeira vez. A multiplicação do número sete sugere um espelhamento de atos e personagens criando duplos, um eficiente elemento gerador de unheimlich, também presente em Inácio.

Kepler $^{7}$ define o duplo, simultaneamente, como idêntico e diferente ao "original", que fascina e provoca reaçôes extremas. Rogério, desde o princípio, afirma seu plano de ser como Inácio e perfaz o ritual de formação almejando a semelhança com o pai, mesmo repudiando seu comportamento. Providencia vestimentas, passa a beber e a freqüentar os mesmos antros, e quer repetir a mesma marca registrada de Inácio: rir de tudo, "rir positivamente dentro da comédia; rir com crueldade e consciência, rir até o último dia, até o dia do Juízo Final..." explica o filho ao pai, quando este pergunta o que "lhe agrada tanto na minha pessoa?”. ${ }^{8}$ Nesse sentido, uma cena curiosa é o primeiro encontro entre Rogério e Lucas, ambos esperavam encontrar Inácio, ou no mínimo alguém muito parecido com ele. Depois de refeitos da mútua decepção, Lucas sentencia ironicamente: "Talvez que dentro de cinco anos o senhor se assemelhe ao que eu imaginava. As pessoas se corrompem tão depressa!". 9

\footnotetext{
${ }^{7}$ KEPLER, 1972.

${ }^{8}$ CARDOSO, 2002, p. 112.

${ }^{9}$ CARDOSO, 2002, p. 41.
} 
São estranhas essas semelhanças familiares, ora desejadas por Rogério, ora observadas por Lucas e Violeta. Rogério é parecido com seus pais, vive o drama familiar de ter sido abandonado e quer reaver seus vínculos paternais, mas o que deveria ser doméstico, conhecido e íntimo é obscuro, indefinido e estranho. Sem memórias claras de sua família, Rogério paradoxalmente deseja e repele o reencontro de ambos e o que deveria ser o retorno à casa primeira torna-se lúgubre e angustiante. Ele reencontra a mãe morta, velada pela solidão e pela miséria, envolta em um lençol, confortada por um par de meias pretas e o amor doentio de Lucas. Observá-la defunta, por entre frestas e pouca luz, o leva enfermo de volta à cama da pensão, acometido por um intenso "sentimento inquietante", segundo suas palavras.

$\mathrm{O}$ agudo incômodo de Rogério diante do familiar o domina por completo. Até seu sobrenome guarda algo de fantasmagórico: Palma, retirado o P ficamos com alma, e é bem a característica íntima dessa gente que o narrador nos apresenta. Se nos detivermos nos significados dos primeiros nomes, veremos que Rogério é aquele que conquistou a fama através da lança e Inácio é o que vem do fogo, ardente, fogoso. ${ }^{10}$ No meio do livro, Rogério, ensimesmado, perdido em seus pensamentos e planos, procura por Inácio em todas as frestas da Lapa. Está desesperado para encontrá-lo e começa a compará-lo com os pobres mortais que povoam a rua. Inácio era maravilhoso, autêntico, poderoso, soberbo, insubstituível. Até que Rogério admite adorálo como a um Deus e concretiza as referências inscritas em seus nomes:

Não direi que tenha escolhido um ídolo de cera, e muito menos de ouro, mas ao pensar hoje no que me atraía tanto naquele homem, encontro, entre vários elementos que os meus olhos o transformavam num paradigma de perfeição, uma lembrança longínqua do fogo, como se já tivesse sido experimentado pelas chamas. [...] o aspecto de boneca que Inácio apresentava, sua pele semelhante à louça experimentada, era do fogo que ele o extraía. Não sei por que essa idéía bizarra não me causava nenhum susto. Farto de caminhar, regressei afinal para casa. Toda a escuridão do mundo parecia se ter concentrado na minha alma. 'Não direi uma palavra a ninguém', pensava. 'Armar-me-ei com meu punhal e, se insistirem, tirarei a vida de alguém’. Eram esses meus planos finais. ${ }^{11}$ (Grifos nossos).

${ }^{10}$ AZEVEDO, 1993.

${ }^{11}$ CARDOSO, 2002, p. 99. 
Já o nome de Lucas Trindade abarca referências mais cristãs. O Trindade poderia sugerir a Santíssima Trindade - O Pai, O Filho e O Espírito Santo reforçando a ligação com Lucas, autor do Terceiro Evangelho do Novo Testamento. Lucas, o autor bíblico, recebeu por missão escrever a história do nascimento, vida e morte de Cristo representando-o como defensor dos pobres, dos fracos e dos excluídos, principalmente crianças e mulheres. As menções a elas são inúmeras e exultantes, conta sobre episódios da vida de Ana, de Isabel, das acompanhantes dos apóstolos, de Maria, de Marta de Betânia, e destaca Maria, mãe de Jesus. O evangelho segundo Lucas valoriza a mulher e sua participação na vida de Cristo. Assim como Lucas Trindade, de Lúcio, tem como principal função contar uma versão dos fatos que redima Stela de todos os erros e a pinte como santa. Ele próprio é considerado santo por Rogério.

As ligações de Lucas com a tradição bíblica, imbuído da missão de matar Inácio e vingar a boa e bela Stela, colocam-no ainda mais antagônico a seu inimigo, pois Inácio é a figuração do demoníaco, conforme veremos a seguir, num outro traço da presença do estranho na novela de Lúcio Cardoso. A idéia de mal e do satânico em Inácio merece maior destaque por ser importante na arquitetura da estranheza inquietante que a novela provoca e por revelar um Lúcio Cardoso em diálogo com a tradição literária.

\section{Demoníaco, maléfico e estranho: a tradição do mal em Inácio}

O tema do demoníaco está presente na tradição literária mundial. Para citar os mais emblemáticos podemos lembrar Le Sage ( $O$ diabo coxo, 1707), Goethe (Fausto, 1806), Dostoievski (Irmãos Karamazov, 1866), além da recorrência temática do mal nas obras de Bernanos, Baudelaire, Julien Green, Nietzsche e Kierkegaard, aliás leituras realizadas por Lúcio Cardoso. No pósguerra, poderíamos citar Thomas Mann (Doutor Fausto, 1947), Fernando Pessoa (Primeiro Fausto), ${ }^{12}$ Paul Valéry (Mon Faust, 1946), Orson Welles

\footnotetext{
${ }^{12}$ Pessoa iniciou sua escrita do Primeiro Fausto em 1908 e a estendeu até a década de 1930. A primeira publicação de 90 poemas dessa obra aconteceu em 1952, por Eduardo Freitas da Costa, primo do poeta, mas a edição brasileira do pesquisador Dúlio Colombini, de 1986, alargou a obra para 231 poemas (COLOMBINI, 1986).
} 
(Time runs, 1950), Julien Green (O inimigo, 1954), Guimarães Rosa (Grande sertão: Veredas, 1956), entre outros.

Em Inácio, Lúcio Cardoso, tradutor de Drácula o homem da noite (1897), de Bram Stoker, e d'O livro de Job (Velho Testamento), retoma essa tradição e, na medida em que a reelabora, imprime em seu texto particularidades de estranhamentos e horror em consonância com seu momento de escritura e publicação - entre a Primeira e a Segunda Guerras Mundiais- e com o cenário local, o bas-fond carioca. Nessa novela, o escritor transitou pela questão do bem e do mal mantendo constante e profícuo diálogo com a tradição, aproveitando as dúvidas e as angústias que Lúcio, arguto leitor da Bíblia, impunha às suas raízes católicas, elevando, principalmente, as questôes temáticas para o nível da linguagem, já que estrutura sua textualidade em consonância e colaboração com a temática do mal.

A novela se desenrola em torno de Inácio - personagem que dá nome ao livro e que se repete nos outros dois títulos da trilogia. ${ }^{13} \mathrm{Um}$ tipo de agente de Satã, aquele que, embora inserido no rebanho dos fieis, secretamente trama para a sua perdição. ${ }^{14}$ Algumas de suas características, como o poder da adivinhação e realizações mágicas, sua vestimenta peculiar, sua juventude eterna ou o fato de ser inominável ou o de contaminar as pessoas que o cercam com uma forte sensação de frio, nos permitem a inserção de Inácio no quadro das personagens que representam o Demo:

O certo é que suas possibilidades causavam-me uma singular fascinação, isto é, sua facilidade, seu poder de arrancar as coisas do vazio, de produzir tudo como um feiticeiro com sua varinha, como alguém que faz explodir um fogo de artifícios... Devo declarar também que, nele, uma das qualidades que mais me impressionavam era a sua capacidade de transfiguração $[\ldots]^{15}$

Conforme já pontuado, desde o começo da novela, encontramos Rogério perturbado por dois desejos antagônicos: o anseio e o temor em relação à Inácio. Ele pensa que Inácio reaparecerá e desenvolve uma digressão

${ }^{13}$ Inácio é a primeira novela da trilogia "O mundo sem Deus", que conta ainda com Baltazar, 1950 (inacabada), e O enfeitiçado, 1954.

${ }^{14}$ NOGUEIRA, 2002.

${ }^{15}$ CARDOSO, 2002, p. 109. 
sobre o possível reencontro. Aí temos a linguagem mágica e misteriosa do narrador que envolve Inácio, como, por exemplo, sua estranha capacidade de adivinhação, a existência de uma "época exata" para seu retorno e o fato de ele não simplesmente voltar, mas "aparecer", "reaparecer":

Por um momento, a pergunta passa rápida pelo meu pensamento: se era ele, realmente, como tinha descoberto o meu endereço? Como podia estar ali naquele minuto, sem ninguém para lhe informar ao menos quem eu fosse? Não haveria um engano em toda essa história? A Duquesa não estaria sendo vítima de uma ilusão? Ora, durante esses últimos tempos eu tinha pensado muito na sua pessoa - revia-o mesmo constantemente, e, poucos dias antes de me levantar, no momento exato em que começara a levantar os meus planos, pensara comigo mesmo: 'Estamos na época exata. Ele não pode deixar de aparecer, e precisamente neste momento'. Por que era a época exata, não o saberei explicar. Como tantas outras coisas, apenas sentia, sem conseguir localizar as raizes dessa estranha intuição. Tudo me dizia, realmente, que ele estava para fazer seu reaparecimento. [...] se fosse realmente ele, estaria vestido do modo pelo qual eu sempre o imaginara, com a roupa com que sempre o vira nos meus sonhos. Homens daquela espécie jamais se vestem de maneira diferente. ${ }^{16}$ (Grifos nossos).

Interessante notar que para ter certeza de que era Inácio, Rogério pergunta sobre as roupas da visita. Duquesa, dona da pensão onde vive, responde, e ele chega à conclusão de que não é Inácio. Essa questão da importância das roupas de Inácio, e de sua aparência física, encontra eco na tradição literária sobre Satã. Originalmente, Satã era o anjo mais belo, mas com a queda do céu, o ex-mensageiro de Luz se transformou numa criatura disforme. Os desenhos dos monges medievais contribuíram muito para a sedimentação desta imagem. Na literatura pré-romântica, o diabo é portador de uma deformação e de vestimentas peculiares: pés fendidos, pernas curtas, manco, roupa escarlate. No romance de Le Sage, 1707, O diabo coxo, o demo vem figurado com pernas de bode, rosto comprido, queixo pontudo, tez amarelada e escura, nariz de suíno, olhos em chamas, além de bigode, boca e lábios que em tudo lembram um animal horrendo.

${ }^{16}$ CARDOSO, 2002, p. 34. 
Mas, a partir do século XIX, a imagem de Satã muda. Já Goethe, em seu Fausto (1806), apresenta um Mefistófeles vaidoso e tão bem apessoado para o Diabo, que passa até pelo dissabor de não ser reconhecido pela bruxa, no capítulo "A cozinha da bruxa". É o próprio Mefistófeles quem explica sua aparência diferente do "normal":

A cultura, outrossim, que lambe o mundo, à roda,

Tem-se estendido sobre o diabo;

O nórdico avejão já não está na moda;

Onde vês garras, chifres, rabo?

E quanto ao pé, que não dispenso, sinto

Que em público me faz de mal visto e de intruso;

Eis por que, como mais de um fidalgão distinto,

Há tempos panturrilhas falsas uso. ${ }^{17}$

Já Thomas Mann, em Doutor Fausto, de 1947, faz Adrian receber a visita de um refinado e intelectualizado Satã, no Capítulo XXV, dedicado ao pacto. Sendo assim, desde o Diabo com panturrilhas, teremos toda uma linhagem de demônios mais elegantes e até abstratos. À guisa de exemplo, no Brasil, Guimarães Rosa, em Grande sertão: Veredas, ${ }^{18}$ não sabemos, à semelhança de Riobaldo, se o Demo existe e nem se fizeram o pacto. $\mathrm{Na}$ novela, Lúcio Cardoso, além de conferir importância ao figurino da personagem demoníaca, ${ }^{19}$ empresta a essas vestimentas algo de escandaloso e exagerado que parece querer ironizar quem as usa:

E o que mais me espantava é que se vestia exatamente como eu imaginara: um terno de xadrez, excessivamente gaiato para um homem comum, e já fora da moda. Tinha um talhe todo especial, apertado na cintura como roupa dos antigos janotas. No bolso, um lenço branco escandaloso voava ao vento como uma enorme rosa desabrochada sobre o incrível costume de xadrez. ${ }^{20}$

${ }^{17}$ GOETHE, 2004, p. 257

${ }^{18}$ ROSA, 1984.

${ }^{19}$ CARDOSO, 2002, p. 85. Rogério repete várias vezes observações, dúvidas e comentários sobre o modo de Inácio se vestir e ele próprio se sente mais poderoso e próximo de realizar seu plano após comprar roupas novas. Ver páginas 35, 46-47, 71-72, 85, 100 e 110.

${ }^{20}$ CARDOSO, 2002, p. 85. 
Esse Diabo, de aparência moderna, acaba corporificando um outro aspecto relevante para os escritores que trabalharam com o mal: a representação do homem moderno e sua degradação. Conforme citamos anteriormente, vários autores do pós-segunda-guerra-mundial vão abordar Fausto (do ponto de vista de sua estreita relação com Mefistófeles) como a representação do homem moderno, individualista, obcecado pelo desejo de dominar o mundo e de pactuar com o mal para conseguir seus objetivos. ${ }^{21}$ À maneira de Inácio e do próprio Rogério (que na verdade visa se tornar um Inácio).

A estranheza de Inácio não se limita às roupas. Com cara de boneca e estilo dândi, ele acumula habilidades mágicas, como não envelhecer, assumindo forma imortal: ${ }^{22}$

- Vamos - disse Lucas -, pois tenho medo de não me controlar. Nem sabe você de que poderes é dotado esse demônio!

- Não acredito nos seus poderes - respondi eu, mais para atiçá-lo do que mesmo por dar crédito às minhas palavras.

- Não? Pois há vários anos que não me abandona, que me persegue dia e noite, sem descanso. Até em sonhos me aparece. E como zomba de mim, como se ri, como bebe e vive satisfeito, esse monstro! E sempre o vi assim com essa fisionomia que jamais envelhece, com o mesmo olhar e a mesma cara de boneca! ${ }^{23}$

Temos aí, além da juventude eterna, a indicação direta de Inácio como um demônio. No trecho também aparece a questão da cara de boneca, que se repete durante o texto, e remete às máscaras de Satã e, por fim, referência a uma entidade dionisíaca que bebe, ri e vive satisfeita. Essa entidade, a exemplo da cultura popular, ${ }^{24}$ impóe ao enunciador dificuldade para pronunciar seu nome. No trecho abaixo, Rogério se admira da resistência de Lucas para dizer o nome de seu pai, mas ele próprio, na maior parte do

${ }^{21}$ WATT, 1997.

${ }^{22}$ A juventude (ligada à sensualidade) é um valor presente no tema do diabólico, tanto que o primeiro pedido de Fausto, de GOETHE, a Mefistófeles (pós-pacto), é o de rejuvenescer. Ver cena "A cozinha da bruxa".

${ }^{23}$ CARDOSO, 2002, p. 86-87.

${ }^{24}$ Basta lembramos Grande sertão: Veredas, de Guimarães Rosa, no qual há mais de 50 nomes para designar o Demônio ou o "o sem-nome". 
tempo, se refere a Inácio como "ele" e, diretamente, nunca como pai e raramente pelo nome próprio:

- Inácio.

Senti que ele não podia pronunciar aquele nome. Dizia a primeira letra e engolia o resto, como um soluço. ${ }^{25}$

Ademais, o clima de terror e medo muitas vezes deixa o entorno de Inácio com ares de inferno. Quando Rogério sente a presença do pai e foge alucinadamente, a descrição do espaço noturno, o suspense, o assovio de Inácio e o jogo esconde-aparece, criado pelas personagens, constituem a narração de um encontro fantasmagórico e monstruoso com o mal que está sempre à espreita. ${ }^{26}$

Num outro momento, em consonância com o jogo de repulsão e atração, Rogério vive o prazer de estar em companhia de Inácio, uma presença carismática e, para ele, possuidora de poderes mágicos, como por exemplo, a capacidade de "ver sem olhar". A descrição de Inácio lembra aí um príncipe, um príncipe do mal, ou um vampiro (é bom recordar que Lúcio traduziu Drácula o homem da noite, de Bram Stoker):

$\mathrm{O}$ temor, a alegria e o respeito paralisaram-me. Ele devia ter-me visto de longe - curiosa faculdade a sua de ver sem olhar para objetos e pessoas -, pois voltou-se rapidamente e me fez sinal com a mão. Em seguida, sem esperar, pôs-se a caminhar rapidamente para a esquina oposta. 'Meus Deus, vai fugir!”, imaginei. Mas não, não era possível que fugisse, tendo vindo ali para me procurar. Acompanhei-o a certa distância, tal como ele próprio parecia desejar. De longe, eu imaginava que ele era mais alto e mais esguio do que eu supusera. Suas roupas - aquelas roupas que um homem decente jamais usaria - eram ainda as mesmas, isto é, um terno xadrez vermelho, muito justo na cintura e muito curto embaixo. Seus pés, grandes e calçados com botinas amarelas, moviamse com estranha agilidade. Em breve reparei em que um automóvel nos esperava à esquina. [...] de uma marca que não existe mais, Benz, se não me engano, grande como uma carruagem $[. ..]{ }^{27}$

\footnotetext{
${ }^{25}$ CARDOSO, 2002, p. 45.

${ }^{26}$ CARDOSO, 2002, p. 65-67.

${ }^{27}$ CARDOSO, 2002, p. 100.
} 
Num último exemplo, vamos observar a referência ao frio. Várias personagens que tiveram seu destino cruzado com o Demo relataram essa experiência frisando a sensação mordaz de frio. É o caso de Fausto, de Goethe e de Adrian, de Mann. Aqui, na cena em que Inácio planeja matar Lucas e revela toda a sua maldade, Rogério sente frio e parece despertar para a ambígua identidade de Inácio:

E, como aquilo se prolongasse, senti de repente um arrepio frio percorrer-me a espinha, descobrindo naquele sorriso permanente e artificial qualquer coisa estranha que eu não conhecia. ${ }^{28}$ (Grifo nosso).

Como no trecho acima, em vários outros momentos ${ }^{29}$ o narrador lança mão de vocabulários próximos ao sentido de estranho; num esforço de comunicar e enredar o leitor na plena sensação de estranheza.

É por meio desse narrador que Lúcio Cardoso constrói um de seus textos mais intensos e multíplice. $\mathrm{O}$ diálogo com a tradição literária e o conceito de estranho de Freud possibilita uma leitura de Inácio que evidencia o atento e delicado trabalho do autor brasileiro com a palavra. Apontando a complexa presença do mal em sua obra. Há questões históricas, estilísticas e filosóficas envolvidas, ${ }^{30}$ tornando Inácio um livro fundamental na questão da produção de Lúcio Cardoso. Os leitores, que não se deixarem levar pela glosa do poeta fingidor, ${ }^{31}$ perseguirão, junto com a complexidade da novela, o fio condutor para entender o projeto e a presença do mal na prosa do autor. Por meio desse livro, percebe-se que suas personagens não apenas padecem do mal, mas também são agentes maléficos, cultivando ódio, vingança e prazer demoníaco. Nesse sentido, o mal, em certos momentos de sua obra - Inácio

${ }^{28}$ CARDOSO, 2002, p. 134 .

${ }^{29}$ Ver alguns exemplos em CARDOSO, 2002, p. 16, 27, 29, 34, 37, 59, 65-66, 88, 100, 109, 134 e 139.

${ }^{30}$ Refiro-me a penetrante presença de Nietzsche e Kierkegaard nas entrelinhas de Lúcio. Porém, não nos aprofundaremos nos apontamentos filosóficos indicados na leitura de Inácio.

${ }^{31}$ Lúcio Cardoso gostava de dizer que escreveu a novela Inácio em quatro dias de fúria. Esse tipo de declaração engrossa o caldo da crítica que vê em Lúcio um autor mais vinculado à "inspiração" do que ao "trabalho", desorganizado com seus originais e até descuidado em sua escrita, tese que uma leitura mais atenta coloca em xeque. 
como exemplo - se configura como fim em si mesmo. Tal aspecto torna a prosa de Lúcio ainda mais instigante, pois conduz o leitor a experimentar a inquietante estranheza de observar sombrias versões familiares, revelando ângulos obscuros, macabros e misteriosos das, aparentemente, domésticas relações entre pais e filhos. Lúcio conduz o leitor a gozar da "coragem para abraçar eternamente a sua sombra negra" ${ }^{32}$

\section{Referências Bibliográficas}

AZEVEDO, Sebastião Laércio. Dicionário de nomes de pessoas. Rio de Janeiro: Civilização Brasileira, 1993.

CARDOSO, Lúcio. Inácio, O enfeitiçado e Baltazar. 3. ed. Rio de Janeiro: Civilização Brasileira, 2002.

FREUD, Sigmund. O estranho (1919). In: . História de uma neurose infantil e outros trabalhos. Edição standard brasileira das obras completas, V. XVII. Rio de Janeiro: Imago, 1996.

GOETHE, J. W. Fausto - Uma tragédia (Primeira parte). Trad. Jenny Klabin Segall. São Paulo: Editora 34, 2004.

KEPLER, C. F. The literature of the second self. University of Arizona: Press Tucson, 1972.

MANN, Thomas. Doutor Fausto. Trad. Herbert Caro. Rio de Janeiro: Nova Fronteira, 1984. (Coleção Grandes Romances)

NOGUEIRA, Carlos Roberto F. O diabo no imaginário cristão. 2. ed. Bauru, SP: Edusc, 2002.

ROSA, João Guimarães. Grande sertão: veredas. 16. ed. Rio de Janeiro: Nova Fronteira, 1984.

PESSOA, Fernando. Primeiro Fausto. 2. ed. São Paulo: Iluminuras, 1986. Org. e introd. de Duílio Colombini.

WATT, Ian P. Mitos do individualismo moderno: Fausto, Dom Quixote, Dom Juan, Robison Crusoe. Trad. de Mario Pontes. Rio de Janeiro: Jorge Zahar, 1997.

${ }^{32}$ CARDOSO, 2002, 126. 


\section{Resumo}

Nas confluências entre o literário e o psicanalítico, o artigo se propõe a apontar a maneira pela qual Lúcio Cardoso constrói a inquietante estranheza de Inácio, a mais forte característica da novela. Também notamos que é por meio desse recurso, em constante diálogo com a tradição literária, que o romancista declara um outro projeto para o mal em sua prosa: agente, ativo e comprometido com o maligno - diferente do que se tem apontado sobre a obra do autor tratar o mal apenas como caminho de purificação para o bem celestial.

\section{Abstract}

In the confluences between literary and psychoanalytic, the article is proposed to point to the way for which Lúcio Cardoso builds the worrying strangeness of Inácio, the strongest characteristic of the short novel. Also we notice what is through this resource, in constant dialog with the literary tradition, that the novelist declares another project for the evil in his prose: agent, active and compromised to the malignant - different thing of which one has been beginning to appear on the work of the author treats the evil you punish like way of purification for the quite celestial one. 